\title{
The diagnostic value of mucosubstances in rectal biopsies from patients with ulcerative colitis and Crohn's disease
}

\author{
M. I. FILIPE AND IAN DAWSON \\ From the Department of Clinical Histochemistry, Westminster Medical School, London
}

SUMMARY Sixty-two biopsies from 36 patients with ulcerative colitis and 29 biopsies from 15 patients with Crohn's disease were studied with special reference to the content of neutral, acid non-sulphated and sulphated mucosubstances. A marked decrease was found in mucosubstance in patients with active ulcerative colitis and was related to the intensity of inflammation in the lamina propria but not to the duration of the disease. In patients with active Crohn's disease there was no corresponding decrease. Techniques for mucosubstances appear to be of value in differentiating between the two diseases in rectal biopsies.

The importance of rectal biopsy in the diagnosis and follow up of ulcerative colitis and Crohn's disease of the large intestine has been emphasized by Matts (1961), Gonzalez-Licea and Yardley (1966), and others. Biopsy also has an important role in attempts to separate these two diseases. There are, however, limitations to the value of conventional histology; for example the histological lesions found in ulcerative colitis are not always specific and can be inseparable from those seen in other inflammations such as bacillary. dysentery. Nor is histology always helpful in the differential diagnosis between ulcerative colitis and Crohn's disease when pathological features of both are present (Lewin and Swales, 1966).

For these reasons many workers have turned to histochemical or ultrastructural techniques for the further evaluation of such biopsies. Ultrastructural changes have been described as of value in detecting disease activity (GonzalezLicea and Yardley, 1966) but none have so far been described which are diagnostic of ulcerative colitis or of Crohn's disease. Monis and Mendeloff (1965) described characteristic changes in the distribution of NADP-linked dehydrogenases and non-specific esterases in ulcerative colitis, but these findings have not been confirmed by other workers (Van Noorden, Thayer, Yesner, and Spiro, 1967; Melnyk, Braucher, and Kirsner, 1967; Filipe, 1968), and there are no ultra- structural changes at the epithelial cell apex to correlate with them.

Other workers have turned to a study of mucosal mucins in colectomy specimens from ulcerative colitis (Greco, Lauro, Fabbrini, and Torsoli, 1967) and ulcerative colitis and Crohn's disease (Hellstrom and Fisher, 1967). This seems a profitable line of approach, bearing in mind that rectal biopsy is easy and relatively innocuous and is being increasingly used by clinicians as a complement to clinical, radiological, and sigmoidoscopic investigations. It was decided to review all rectal biopsies of confirmed cases of ulcerative colitis and Crohn's disease of the large bowel seen in the Vincent Square Laboratories of Westminster Hospital over the past ten years, using histochemical techniques for mucosubstances to assess their value as an aid to definitive differential diagnosis between the two conditions.

\section{Material and Methods}

The studies presented here were on rectal biopsies from patients treated at the Gordon Hospital (Westminster Group) during the period 1958 to 1968 and in all of them a diagnosis of either ulcerative colitis or Crohn's disease of the large 


\begin{tabular}{|c|c|c|c|c|c|c|c|c|}
\hline \multirow[t]{2}{*}{ Disease } & \multicolumn{8}{|c|}{ Histology } \\
\hline & Acute & $\begin{array}{l}\text { Chronic } \\
\text { Active }\end{array}$ & Quiescent & Fulminant & $\begin{array}{l}\text { Non- } \\
\text { specific }\end{array}$ & Normal & $\begin{array}{l}\text { Typical } \\
\text { (Group } \\
l)^{1}\end{array}$ & $\begin{array}{l}\text { Borderline } \\
\text { (Groups } \\
2-3)^{1}\end{array}$ \\
\hline \multicolumn{9}{|c|}{ Ulcerative colitis ( 36 patients) } \\
\hline & 11 & 32 & 2 & 3 & 13 & 1 & & \\
\hline \multicolumn{9}{|c|}{ Total 62 rectal biopsies } \\
\hline \multicolumn{9}{|c|}{ Crohn's disease (15 patients) } \\
\hline Total 29 & rectal & piopsies & & & & & & \\
\hline
\end{tabular}

Table I Histological classification of the cases studied

${ }^{1}$ According to classification of Lewin and Swales (1966)

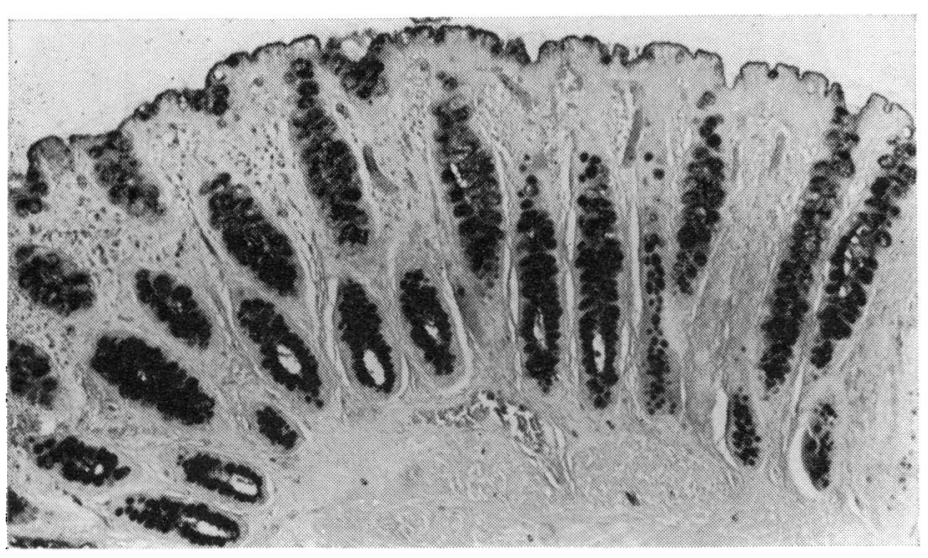

Fig. 1 Normal rectal mucosa to show sulphated mucosubstance (dark staining high iron diamine and alcian blue) predominantly in the lower two-thirds and a mixture of sulphated and acid non-sulphated mucosubstance in the upper third. $\times 60$

intestine was confirmed histologically in colectomy specimens.

All patients on whom a rectal biopsy was performed but no operation specimen was available for pathological confirmation are excluded. A total of 91 rectal biopsies from 51 patients fulfilled these conditions. Thirty-six patients (62 rectal biopsies) suffered from ulcerative colitis and 15 (29 rectal biopsies) were cases of Crohn's disease affecting the large bowel. All specimens were initially fixed in $10 \%$ formalin, embedded in paraffin, and stained with haematoxylin and eosin.

The 62 rectal biopsies from cases of ulcerative colitis were divided into six categories according to the histological findings using the classification of Dawson and Pryse-Davies (1959). The 29 rectal biopsies from patients with Crohn's disease were also divided in four groups according to the histological type of lesions observed, broadly based on that of Lewin and Swales (1966).

The classification of mucosubstances is confused (Spicer, Leppi, and Stoward, 1965) and it is not proposed to discuss it here. Epithelial mucosubstances are probably all glycopoly- peptides in which carbohydrates are linked to the side chains of amino acids forming the polypeptide strand through covalent bonds (Jeanloz, 1960, 1963; Gottschalk, 1962). The carbohydrate units are either disaccharides or polysaccharides of low molecular weight, often with a terminal sialic acid group. Histocnemical techniques identify the carbohydrate as opposed to the polypeptide component, and allow a simple classification into neutral, acid non-sulphated, and sulphated mucosubstances. The following techniques have been used on sections from the original paraffin blocks. Periodic acid-Schiff to test for neutral mucosubstances, alcian blue at $p \mathrm{H} 2.5$ followed by periodic acid-Schiff to test for acid non-sulphated and neutral mucosubstances (Mowry and Morard, 1957), and high iron diamine followed by alcian blue at $p \mathrm{H} 2.5$ for acid sulphated and acid non-sulphated mucosubstances (Spicer, 1965).

The amount of mucosubstance present was estimated semiquantitatively on a visual basis using a scale from 0 to +++ with $++/+++$ representing the normal.

\section{Results}

\section{CLINICAL FINDINGS}

The age at first onset of symptoms lay between 13 and 78 years (mean 45.5 ) for 36 patients with ulcerative colitis, with a fairly even scatter between the third, fourth, and fifth decades and a considerable number beginning in the seventh decade, and between 11 and 50 years (mean 30.5) for 15 cases with Crohn's disease with a maximum incidence in the second and third decades. The duration of symptoms up to the time of biopsy varied from one month to 23 years in colitics, being less than four years in the majority, and in Crohn's disease it varied from four to 27 years, being four to eight years in the majority. The sex incidence was equal in both ulcerative colitis and Crohn's disease.

\section{HISTOLOGICAL FINDINGS}

There were 62 biopsies from 36 patients with ulcerative colitis, classified as shown in Table $I$. In some patients who had more than one biopsy the_histological pattern changed as the disease progressed. There were 29 biopsies from 15 patients with Crohn's disease classified as shown in Table $I$.

\section{HISTOCHEMICAL FINDINGS}

In the normal adult rectal mucosa the lower twothirds of the crypt contains goblet cells with a predominance of sulphated mucosubstances but no neutral mucosubstance, while the goblet cells of surface epithelium and the upper one-third 


\begin{tabular}{|c|c|c|c|c|c|}
\hline \multirow[b]{2}{*}{ Histology } & \multicolumn{5}{|c|}{ Amount of Mucus (No. of Cases) } \\
\hline & olt & $+1++10$ & $++1+++$ & $\begin{array}{l}\text { Variable } \\
\text { ol }+1++1+++\end{array}$ & Total \\
\hline $\begin{array}{l}\text { Ulcerative Colitis } \\
\text { Acute } \\
\text { Chronic active } \\
\text { Quiescent } \\
\text { Fulminant } \\
\text { Non-specific lesions } \\
\text { Normal }\end{array}$ & $\begin{array}{r}4 \\
18 \\
1\end{array}$ & $\begin{array}{r}5 \\
9 \\
1 \\
11\end{array}$ & $\begin{array}{l}2 \\
2 \\
2 \\
1^{1}\end{array}$ & $\begin{array}{l}5 \\
1\end{array}$ & $\begin{array}{r}11 \\
32 \\
2 \\
3 \\
3 \\
13 \\
1\end{array}$ \\
\hline Total & 23 & 26 & 7 & 6 & 62 \\
\hline $\begin{array}{l}\text { Crohn's Disease } \\
\text { Typical lesion } \\
\text { Borderline cases } \\
\text { Non-specific lesions } \\
\text { Normal }\end{array}$ & & 1 & $\begin{array}{r}13 \\
5 \\
5 \\
4\end{array}$ & 1 & $\begin{array}{r}15 \\
5 \\
5 \\
4\end{array}$ \\
\hline Total & & 1 & 27 & 1 & 29 \\
\hline
\end{tabular}

Table II Variations in the amount of mucosubstance in mucosa in relation to the histological picture $1+$

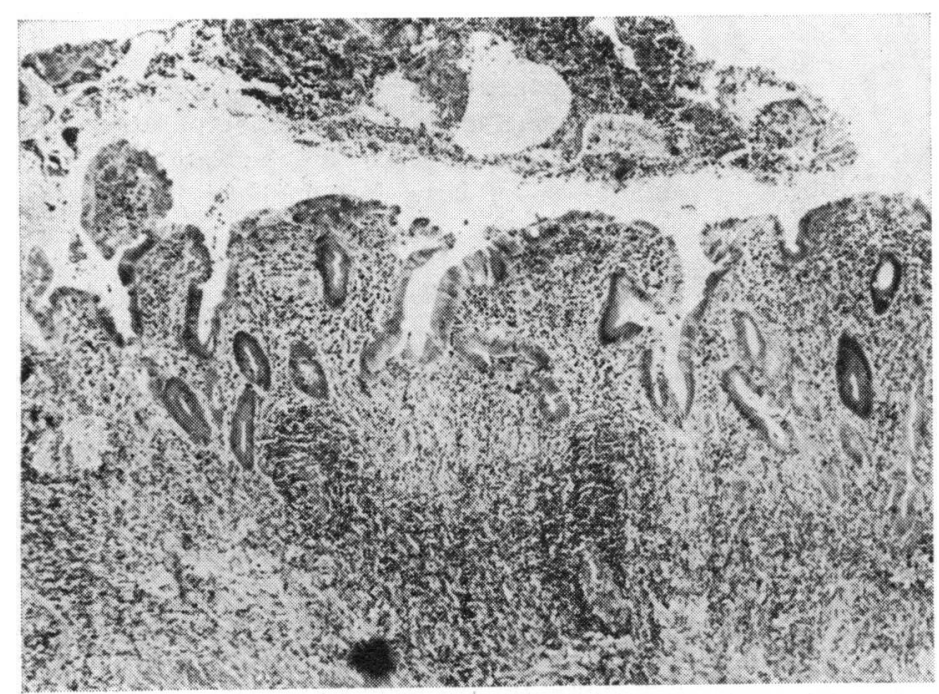

Fig. 2 Rectal mucosa in chronic active ulcerative colitis. (Haematoxylin and eosin) $\times 52$.

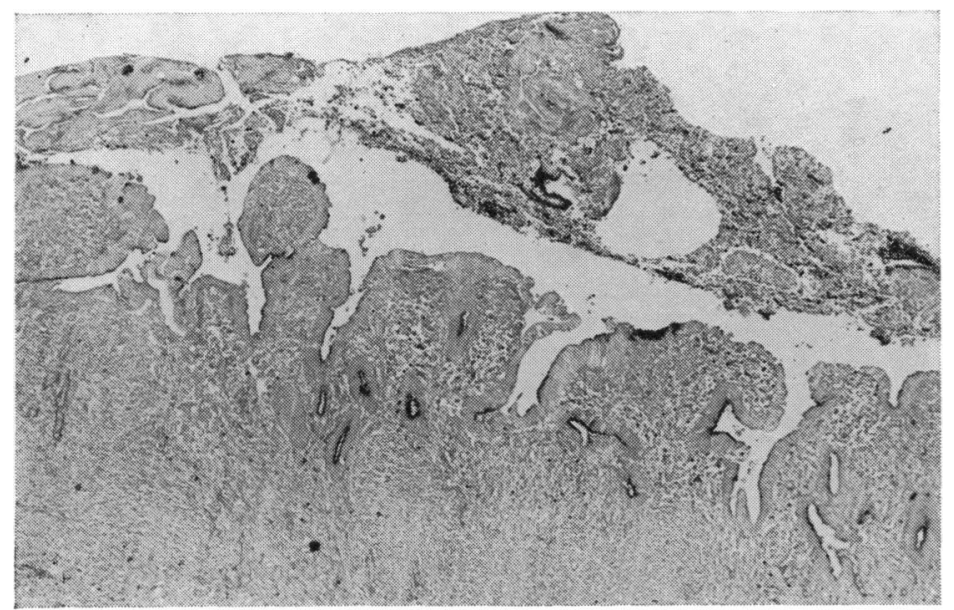

\begin{tabular}{|c|c|c|c|c|}
\hline \multirow[b]{3}{*}{$\begin{array}{l}\text { Histology } \\
\text { Inflammatory } \\
\text { Infiltrate }\end{array}$} & \multicolumn{4}{|c|}{ Amount of Mucus } \\
\hline & \multicolumn{2}{|c|}{ Ulcerative Colitis } & \multicolumn{2}{|c|}{ Crohn's Disease } \\
\hline & $o l+1++$ & $\begin{array}{l}++1+++ \\
\text { or Variable }\end{array}$ & ol $+1++$ & $\begin{array}{l}++1+++ \\
\text { or Variable }\end{array}$ \\
\hline \multirow{2}{*}{$\begin{array}{l}\text { Heavy } \\
\text { Moderate } \\
\text { Mild or } \\
\text { normal }\end{array}$} & $\begin{array}{l}29 \\
11\end{array}$ & $\begin{array}{l}7 \\
7\end{array}$ & $\begin{array}{l}1 \\
0\end{array}$ & $\begin{array}{r}7 \\
11\end{array}$ \\
\hline & 5 & 3 & 1 & 9 \\
\hline Total & 45 & 17 & 2 & 27 \\
\hline
\end{tabular}

Table III Relationship between the amount of mucus in the mucosa and the degree of inflammation in lamina propria

contain a mixture of sulphated and non-sulphated acid mucosubstances, with a variable small amount of neutral mucosubstance (Figure 1). The rectal mucosa of children aged from 2 days to 8 years shows a similar pattern (Filipe, 1969).

An attempt was made to classify any alteration in the amount of mucosubstance in the biopsies in terms of sulphated, acid non-sulphated, or neutral mucosubstance. In any general reduction in the amount of mucosubstance, both sulphated and acid non-sulphated mucosubstances decrease, but this reduction affects the non-sulphated less than the sulphated. No increases above normal were found in any mucosubstances.

Table II shows the semiquantitative findings for mucosubstances related to the different histological patterns in ulcerative colitis and in Crohn's disease. In both diseases where polypoid zones were present in the biopsies non-polypoid zones were chosen without extensive ulceration for the estimations, since it was found that polypoid zones invariably contained abundant mucosubstances, and severely ulcerated zones have insufficient mucosa for reliable estimates. The findings show clearly a decrease in mucosubstances in the majority of cases of ulcerative colitis but no corresponding decrease in Crohn's disease (Figures 2 to 6 ).

A correlation of the amount of mucosubstance present with the duration of disease was next attempted but no positive correlation could be found. An attempt to correlate the amount of mucosubstance with the degree of inflammation in the lamina propria was (Table III) more successful. In the colitic group, 36 of the 62 rectal biopsies had a heavy inflammatory cellular infiltrate in the lamina propria (Fig. 2), and 29 in this group had a marked generalized decrease in mucosubstance and four a patchy decrease (Fig. 3), while only three had normal amounts. Eighteen biopsies showed a moderate inflammatory infiltrate of which 11 showed a marked decrease in mucosubstances, while seven showed slight decreases. Eight showed mild inflammatory

Fig. 3 Serial section of biopsy in Fig. 2 to show the marked decrease in mucosubstance. (High iron diamine and alcian blue) $\times 51$. 


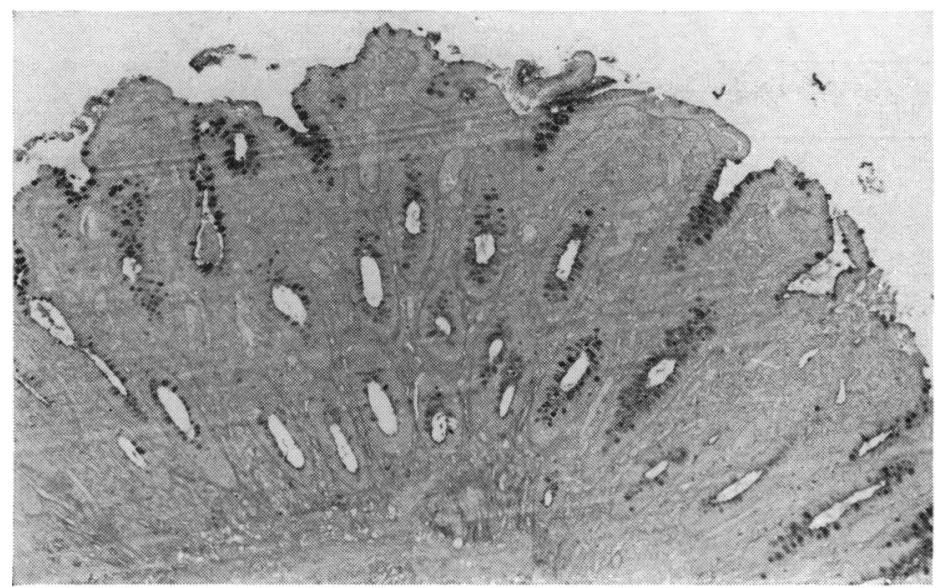

Fig. 4 Rectal mucosa in acute ulcerative colitis. There is a marked decrease in mucosubstance although many gland elements remain. (High iron diamine and alcian blue) $\times 49$.

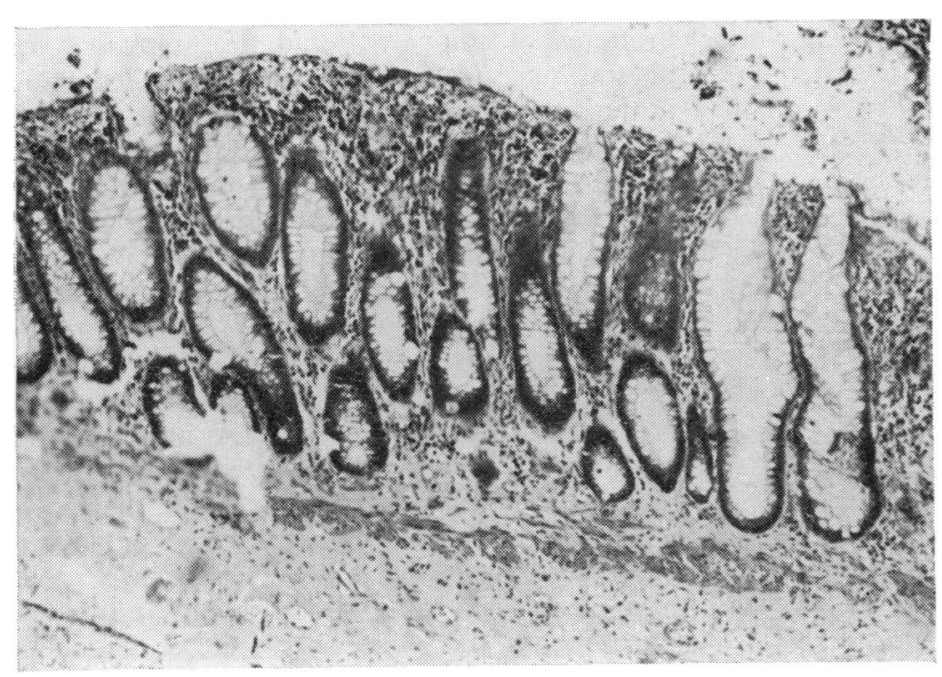

Fig. 5 Rectal mucosa in Crohn's disease showing moderate inflammation in lamina propria. There were characteristic lesions in submucosa and serosa. (Haematoxylin and eosin) $\times 36$.

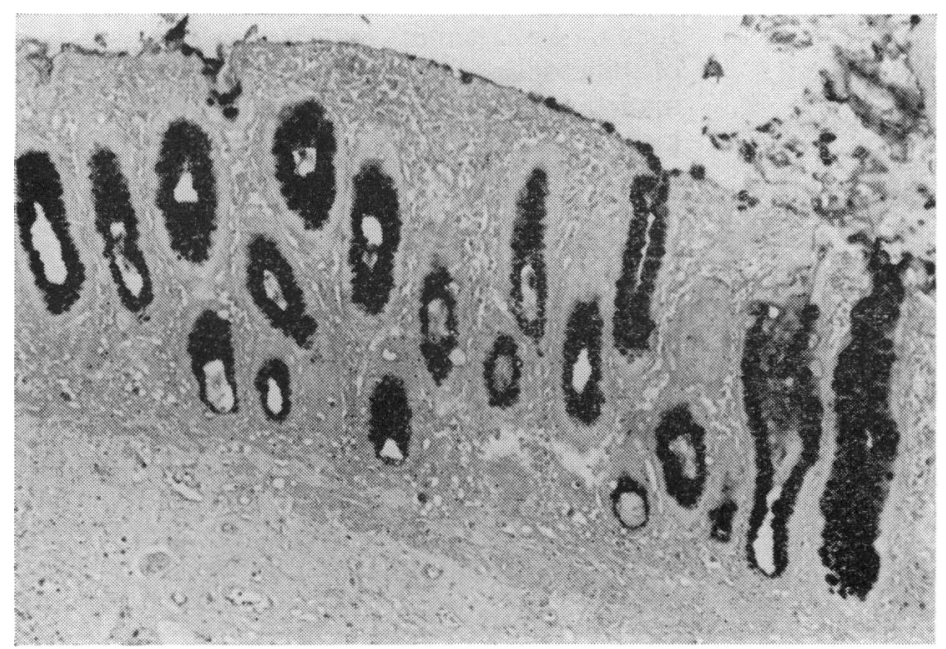

infiltrate, and three of these showed moderate decrease in mucosubstances. In the group with Crohn's disease, although eight biopsies showed severe and 21 moderate or mild inflammatory changes in the lamina propria (Figs 5 and 6), the mucosubstances were reduced only in two of the biopsies.

Finally those patients were considered from whom two or more biopsies were available at intervals and an attempt made to was correlate the amount of mucosubstance present with the progression, or regression, of the disease as judged histologically. It was found that, in general, healing and mucosal regeneration with diminution of inflammatory reaction, parallel an increase in mucosubstances (Figures 7 and 8).

It will be clear from these findings that most cases of ulcerative colitis show a decrease in mucosubstance while most cases with Crohn's disease do not. Fourteen out of the 91 biopsies, all diagnosed as ulcerative colitis, showed a normal mucosubstance content which on this supposition was not in keeping with the histological diagnosis. Before regarding these as a definite negative correlation it was decided to review both the original biopsies and the operation specimens, since in the laboratory the separation of large intestinal Crohn's disease from ulcerative colitis was only made with any confidence after 1963.

Of these 14 cases, three were reclassified as Crohn's disease, three confirmed as ulcerative colitis while eight still defied positive identification, falling into types II and III of Lewin and Swales (1966) in which there are macroscopic and microscopic features suggestive, but not conclusive, of Crohn's disease. The experience in a considerable number of such cases points to conclusion that where, after considering the clinical history, radiology, and histology of a resected colon, there is still doubt as to whether the condition is Crohn's disease or colitis, the disease will behave as Crohn's disease rather than colitis. If this be accepted, then the normal mucosubstance is in keeping with this opinion.

\section{Discussion}

When a patient presents with clinical evidence of proctitis or colitis, and specific bacterial or protozoal inflammation can be excluded, the diagnosis usually rests between non-specific proctitis, ulcerative colitis, and Crohn's disease, and then rectal biopsy is often performed to elucidate it. Although there are specific histological features which may allow of a definite diagnosis

Fig. 6 Serial section of biopsy in Fig. 5 to show normal content of mucosubstance. (High iron diamine and alcian blue) $\times 36$. 


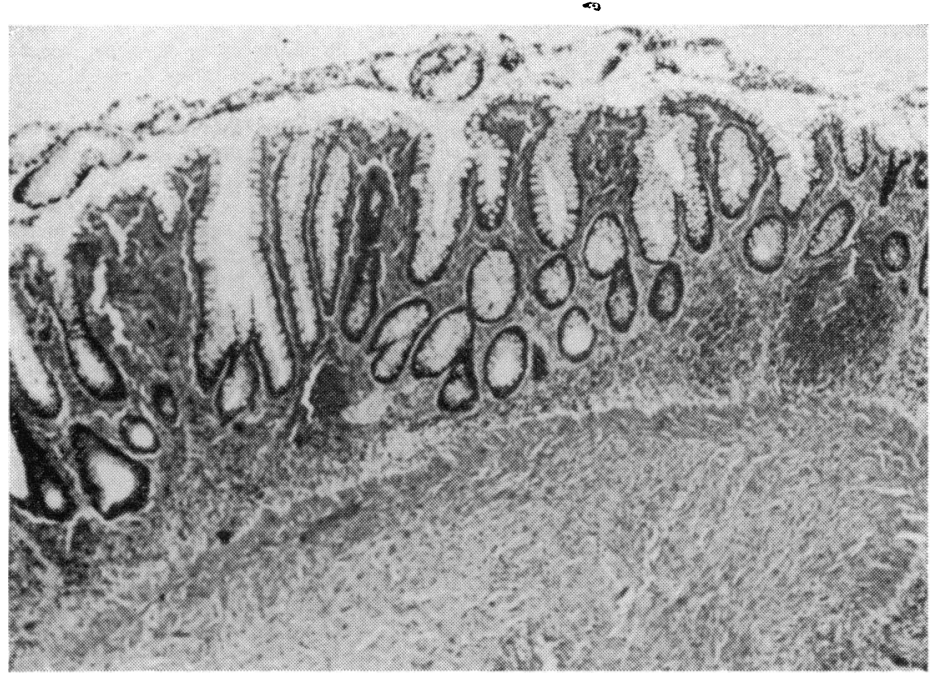

Fig. 7 Rectal mucosa from the same patient as Fig. 2, biopsy taken three years later. There is considerable healing but still some evidence of activity. (Haematoxylin and eosin) $\times 35$.

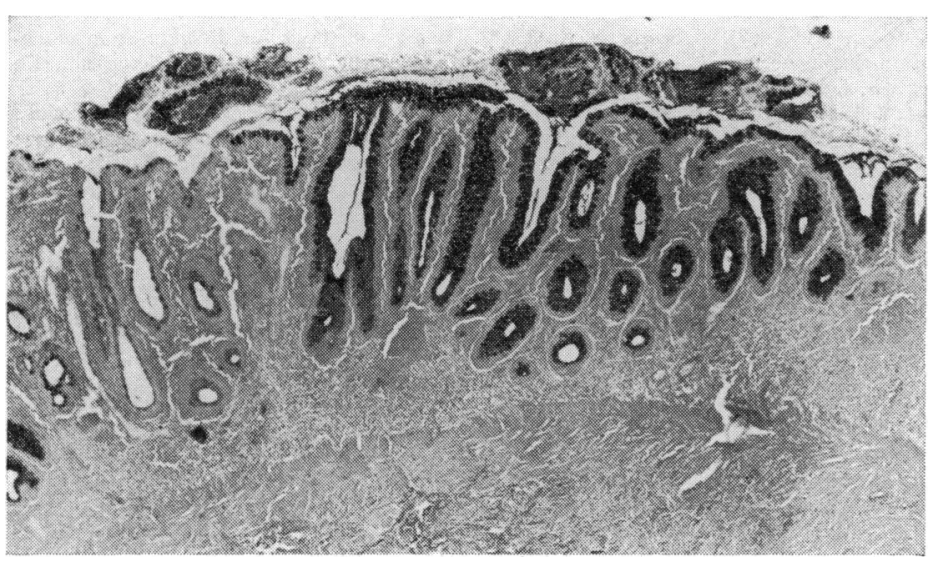

Fig. 8 Serial section of biopsy in Fig. 7. The regenerated epithelium contains mucosubstances but there is still a diminution in the zone of active disease. (High iron diamine and alcian blue) $\times 40$.

of Crohn's disease or of ulcerative colitis (Lockhart-Mummery and Morson, 1960; Janowitz and Present, 1966; Hawk and Turnbull, 1966; Gonzalez-Licea and Yardley, 1966) two problems commonly arise. First the biopsy may show only 'non-specific inflammation' and the diagnosis remains in doubt; second even when the clinical and radiological findings make it clear that the patient suffers either from ulcerative colitis or from Crohn's disease, the biopsy does not always differentiate clearly between them (Lewin and Swales, 1966). Both aspects of this problem are being studied but only the second is reported on and discussed here.

Certain definite conclusions can be drawn from the observations. In biopsies from patients with proven ulcerative colitis, if assessment of mucosubstances is made in zones free from severe ulceration or polypoidal hyperplasia, there is a moderate or marked diminution in sulphated and acid non-sulphated mucosubstances in nearly all cases. This reduction bears a definite relationship to the degree of inflammatory cellular infiltration of the lamina propria, but not to the duration of the disease. This finding in rectal biopsies is similar to that described in colectomy specimens "(Hellstrom and Fisher, 1967; Greco et al, 1967; Filipe, 1969) and may at first be thought to parallel the observation that rectal involvement is more common in colitis than in Crohn's disease. In this series, however, as in that of Hawk and Turnbull (1966), histological rectal involvement in Crohn's disease, with inflammatory change in the lamina propria, is common but reduction in mucosubstances is rare, pointing to an essential and significant difference between the two conditions. This difference, though not absolute, is of considerable help in differential diagnosis. Such a difference is perhaps not surprising since: ulcerative colitis is primarily a diffuse mucosal inflammation, whereas Crohn's disease often involves the whole thickness of the bowel wall without such severe mucosal damage (Morson, 1966).

The differences in amount and type of mucosubstance seen in the different histological patterns of ulcerative colitis are not sufficient to allow these patterns to be distinguished on histochemical grounds alone, but in general it may be said that in fulminating and acute active cases of short duration the decrease in mucosubstances is slight or moderate, and that in chronic active cases it is moderate or severe, and in quiescent cases tends to revert again towards normal. These findings may be of value in assessing the progress of the disease and the effects of medical treatment.

When the mucosubstances present were considered in terms of their neutral, acid nonsulphated, and sulphated content, no loss of mucosubstance was found to differ sharply between sulphated and acid non-sulphated, though in general the mucosubstances which remained seem to be rather more acid nonsulphated than sulphated. This might be explained by the relative immaturity of newly formed cells following an alteration in cellular turnover due to damage of the regenerating zone in the fundus of the crypt (Greco et al, 1967). The differences are not sufficiently distinct to be of any diagnostic value.

In conclusion, it is felt that the addition of investigations for mucosubstances to the conventional histological assessment on rectal biopsies helps materially in the distinction of ulcerative colitis, in which mucosubstances are markedly reduced, from Crohn's disease, in which they are present in normal or slightly reduced amounts. This distinction remains in the presence of marked inflammation of the lamina propria and equivocal histology. Current studies on the 
mucosubstances in non-specific proctitis may help further in the differential diagnosis of proctocolitis on rectal biopsy.

Our thanks are due to the surgical staff of the Gordon Hospital, Westminster Group, under whose care the patients were, to Miss Jean Sowden for technical assistance, to the Photographic Department of Westminster Medical School for the finished prints, and to Miss Jill Ashby for secretarial help. One of us (M.I.F.) was in receipt of a grant from the British Empire Cancer Campaign which we gratefully acknowledge.

\section{References}

Dawson, I. M. P., and Pryse-Davies, J. (1959). The developmen of carcinoma of the large intestine in ulcerative colitis. Brit. J. Surg., 47, 113-128.

Filipe, M. I. (1968). Some aspects of the histochemical enzyme distribution in colon and rectum. Normal and pathological. In Symposium for Histochemistry, Hamburg, September 1968.

Filipe, M. I. (1969). Value of histochemical reactions for mucosubstances in the diagnosis of certain pathological conditions of the colon and rectum. Gut, 10, 577-586.

Gonzalez-Licea, A., and Yardley, J. H. (1966). Nature of the tissue reaction in ulcerative colitis. Light and electron microscopic findings. Gastroenterology, 51, 825-840.

Gottschalk, A. (1962). The relation between structure and function in some glycoproteins. Perspect. Biol. Med., 5, 327-337.

Greco, V., Lauro, G., Fabbrini, A., and Torsoli, A. (1967). Histochemistry of the colonic epithelial mucins in normal subjects and in patients with ulcerative colit is. A qualitative and histophotometric investigation. Gut, 8, 491-496.

Hawk, W. A., and Turnbull, R. B., Jr. (1966). Primary ulcerative disease of the colon. Gastroenterology, 51, 802-805.
Hellstrom, H. R., and Fisher, E. R. (1967). Estimation of mucosal mucin as an aid in the differentiation of Crohn's disease of the colon and chronic ulcerative colitis. Amer. J. clin. Path., 48, 259-268.

Janowitz, H. D., and Present, D. H. (1966). Granulomatous colit is: pathogenic concepts. Gastroenterology, 51, 778-787.

Jeanloz, R. W. (1960). The nomenclature of mucopolysaccharides. Arthr. and Rheum., 3, 233-237.

Jeanloz, R. W. (1963). Recent developments in the biochemistry of amino sugars. Advanc. Enzymol., 25, 433-456.

Lewin, K., and Swales, J. D. (1966). Granulomatous colit is and atypical ulcerative colitis. Histological features, behaviour, and prognosis. Gastroenterology, 50, 211-223.

Lockhart-Mummery, H. E., and Morson, B. C. (1960). Crohn's disease (regional enteritis) of the large intestine and its distinction from ulcerative colitis. Gut, 1, 87-105.

Matts, S. G. F. (1961). The value of rectal biopsy in the diagnosis of ulcerative colitis. Quart. J. Med., 30, 393-407.

Melnyk, C. S., Braucher, R. E., and Kirsner, J. B. (1967). Regeneration of the human colon mucosa. Morphologica and histochemical study. Gastroenterology, 52, 985997.

Monis, B., and Mendeloff, A. I. (1965). Studies in ulcerative colitis: TPN-linked dehydrogenases and nonspecific esterases in rectal biopsy specimens. Gastroenterology, 48, 173-184.

Morson, B. C. (1966). Discussion to Symposium-Newer biological concepts in ulcerative colitis and related diseases. Gastroenterology, 51, 807-808.

Mowry, R. W., and Morard, J. C. (1957). The distribution of acid mucopolysaccharides in normal kidneys, as shown by the alcian blue-Feulgen (AB-F) and alcian blue-periodic acidSchiff (AB-PAS) stains. (Abstract.) Amer. J. Path., 33, 620621 .

Van Noorden, S., Thayer, W. R. Jr, Yesner, R., and Spiro, H. M (1967). Some histochemical studies on intestinal epithelium with particular reference to ulcerative colitis and other inflammatory conditions. J. Path. Bact., 94, 13-18.

Spicer, S. S. (1965). Diamine methods for differentiating mucosubstances histochemically. J. Histochem. Cytochem., 13, 211-234.

Spicer, S. S., Leppi, T. J., and Stoward, P. J. (1965). Suggestions for a histochemical terminology of carbohydrate-rich tissue components. J. Histochem. Cytochem, 13, 599-603. 